\title{
EXTRATERRITORIALIDADE E PROTEÇÃO DA LIVRE-CONCORRÊNCIA
}

\author{
Paulo Borba Casella \\ Professor Associado do Departamento de Direito \\ Internacional da Faculdade de Direito da \\ Universidade de São Paulo'
}

\begin{abstract}
Resumo:
A evolução da aplicação extraterritorial da legislação antitruste resulta da crescente e irreversível internacionalização das atividades econômicas. Quer doutrinária como jurisprudencialmente, destaca-se a questão dos efeitos e a validade da adoção deste critério, como elemento de conexão à luz do Direito Internacional, público e privado. Do ponto de vista da proteção do interesse público, apontamse diferenças da legislação antitruste brasileira em relação à européia e à norteamericana, destacando: o tratamento "per se". a responsabilidade objetiva e a natureza não-penal da legislação antitruste.

O conceito de soberania, e os daí resultantes limites do exercício da Jurisdição nacional, devem se adequar às exigências operacionais da nova realidade política, social e econômica, como exprime o desenvolvimento da incidência extraterritorial das normas de defesa da concorrência, na tentativa de proteger os livres mercados, diante da atuação difusa internacionalmente promovida pelos agentes econômicos, decorrência direta do aumento das relações comerciais internacionais e da atuação de empresas e grupos econômicos transacionais.
\end{abstract}

\begin{abstract}
:
The evolution of extraterritorial application of antitrust legislation is the outcome of growing and irreversible internationalization of economic activities. Both from scholarly as well as case-law points of view, is to be stressed the issue of effects, and the validity of the adoption of this criterium as the International Law localizer, both public and private. From the viewpoint of the protection of public interest, are to be noted the differences of Brazilian vis-à-vis American and European
\end{abstract}

1. O autor descja agradecer a colaboração de Rodrigo Elian Sanchez na pesquisa c levantamento dos dados para o presente artigo. 
legislation, with emphasis: the per se treatment and the objective responsibility as well as the non-criminal nature of antitrust legislation.

The concept of sovereignty, and the ensuing limits of the exercice of national Jurisdition, have to be adequated to the operational requirements of the new political, social and economic reality, as expressed by the development of extraterritorial effect of rules for protection of competition, in an attempt to protect free markets, in view of the internationally promoted multiplied action of economic agents, directly resulting from the increase of international trade relations and the action of transnational corporations and economic groups.

Unitermos: livre-concorrência; extraterritorialidade da jurisdição.

\section{Mudança Contextual e Operacional}

O conceito antes internacionalmente vigente para a delimitação territorial da jurisdição em matéria de proteção da livre-concorrência há de ser adequado aos imperativos operacionais que assegure a este a consistência com as necessidades colocadas pela prática, sob pena de ineficiência dessa atuação.

A questão já se colocou em relação a outras jurisdições, em décadas passadas, e tem de ser dimensionada, no Brasil, em relação ao ordenamento jurídico brasileiro, com relação aos nossos tribunais e autoridades na área. Em boa medida, o mesmo se há de considerar e dimensionar em relação ao mercado integrado em gestação, difícil e conturbada, no contexto do Mercado Comum do Sul, o Mercosul.

O imperativo da proteção da livre concorrência, combinado com o dever do Estado de zelar pela manutenção das regras de jogo do mercado, não pode se deter diante de inconsistentes alegações, de caráter formal, tendentes a restringir a aplicação na sua extensão necessária, das regras de proteção da livre concorrência. Diante da mudança do contexto, tem de ser adaptadas, de modo consentâneo, as regras às quais competirá tutelar as relações entre autoridades nacionais, à luz da crescentemente internacionalizada atuação dos grupos econômicos transnacionais ou multinacionais.

A aplicação extraterritorial da legislação antitruste, é decorrência da evolução e consolidação do direito da concorrência na tentativa de se conformar com o avanço da internacionalização da economia mundial, suscitando novas reflexões acerca do conceito de soberania, e como consequiência, novas reflexões acerca dos limites aceitáveis e viáveis de exercício da Jurisdição nacional. Afim de se dar conta das demandas da sociedade, o Estado deve se adequar à nova realidade, na qual os governos 
tem menos recursos e menos ampla gama de extensão de poder, enfrentando realidade social mais complexa, onde os atores são mais autônomos e fluídos. Em tal panorama, o Estado ainda tem a desempenhar papel de suma importância, pois não há outra instituição ou agente capaz de atender às demandas coletivas da sociedade contemporânea. É, porém, imperioso que a reformulação de certos conceitos, como de Jurisdição nacional, para que o Estado fique em consonância com esta nova realidade.

A incidência extraterritorial das normas de defesa da concorrência decorre de imperativo categórico da operação transnacional de grupos econômicos, sob pena de se fazer totalmente inócua a tentativa de proteção dos livres mercados. Na mesma e exata medida em que operam internacionalmente os agentes, há que se coibir, mediante ação das legislações e jurisdições nacionais os efeitos nefastos dessas práticas sobre cada um dos mercados.

A realidade impõe a necessidade de busca de proteção eficiente dos livres mercados, ao amparo da lei. Referida noção de trabalho é decorrência direta do aumento das relações comerciais internacionais e da atuação de empresas transacionais.

A aplicação extraterritorial das normas antitruste teve marco relevante em caso, da jurisprudência norte-americana, no julgamento de United States $v$. Alcoa ${ }^{2}$ (1945), no qual se determinou a possibilidade de aplicação do Sherman Act, quando a prática produzisse impacto qualificado no comércio norte-americano. No entendimento da Corte, o autor da demanda deveria demonstrar que os atos impugnados tinham intenção de afetar as importações norte-americanas e tiveram tal efeito ${ }^{3}$

Declarou o magistrado, ao julgar o caso Alcoa, em 1945, que "um Estado pode impor obrigações até mesmo a pessoas não submetidas à autoridade deste Estado, por conduta praticada fora destas fronteiras, que tenham conseqüencias dentro das fronteiras do Estado, condutas estas que o Estado reprova" ao menos na medida em que estes efeitos foram intencionalmente causados.

2. A ação tcve por objcto o ajustc, na Suíça, de cartcl cntre cmpresas não nortc-amcricanas, com a constituição de uma socicdade denominada Alliance. O cartel tinha como cscopo a delimitação da produção $\mathrm{dc}$ lingotcs de Alumínio, fabricados pclos fabricantes do acordo, pcla imposição de quotas proporcionais às açõcs que os sócios tinham subscrito. Ajustou-sc que as exportaçõcs para os Estados Unidos deveriam ser incluídas nas quotas cstabclccidas. A Alcoa, pcssoa jurídica nortc-amcricana não cra partc do cartcl, porćm scus acionistas amcricanos tivessem participação majoritária na Aluminium Limited, cmpresa constituida no Canadá c partícipe do acordo. O ajustc rcalizado fora do território americano, fícou sujeito às lcis amcricanas, por causar cfeitos dentro de scu território, já que as cxportações de lingotes de Alumínio cstavam sujcitas as limitações das quotas de produção, afetando o funcionamento sadio da cconomia deste pais.

3. "were intended to affect (U.S.) imports and did affetct them" 
Segundo Myres McDougal: "Quando a Suiça ou Canadá ou qualquer outro pais emprega seu aparato governamental para proteger empresários, em atividades que prejudiquem o funcionamento sadio do processo comunitário dentro dos EUA, eles estão interferindo com os negócios internos e domésticos dos EUA, tanto quanto os EUA podem estar interferindo com os negócios de outros paises, ao aplicar suas leis antitruste às atividades causadoras dos danos. Acordos feitos por empresários privados na Suiça ou no Canadá, ostensivamente protegidos pelas leis desses paises, podem afetar ou determinar os preços que eu devo pagar, dentro dos EUA, pelo aluminio ou relógios. Num mundo interdependente, a interferência recíproca dos Estados no processo comunitário, inclusive nas questões econômicas é inevitável. A questão é por que principios e procedimentos tal interferência pode ser moderada e reciprocamente tolerada na manutenção e expansão da economia internacional." 4

Esta também é a orientação do art. $2^{\circ}$ da Lei n. 8.884/94: "Aplica-se esta lei, sem prejuizo de convenções e tratados de que seja signatário o Brasil, às práticas cometidas no todo ou em parte no território nacional ou que nele produzam ou possam produzir efeitos" Cumpre ressaltar a distinção de alcance e sentido entre "produzam" e "possam produzir efeitos", presente na legislação nacional, como critério de incidência da norma nacional.

Diversamente do Brasil, nos EUA, os casos de cartel, são criminais, decorrendo desta afirmação, a necessidade de provar a culpa do agente. A legislação pátria imputa responsabilidade objetiva ao agente (art. 20, caput, Lei n. 8.884/94).

A natureza da legislação brasileira antitruste não é penal, não sendo admitida a extensão de princípios penais para seu bojo. O Direito Penal tem seu campo de aplicação específico.

Essas condições para a aplicação extraterritorial da lei, desenvolvida no caso Alcoa, foram consolidadas no Foreign Trade Antitrust Improvements Act (FTAIA), de 1982, consoante o qual o efeito qualificado no mercado norte-americano, que justifique a aplicação de sua legislação antitruste é aquele "direto, substancial e razoavelmente previsível"s. A teoria dos efeitos, possibilita a real aplicação da jurisdição

4. Josć Carlos de Magalhães, “A aplicação cxtratcrritorial de lcis nacionais”, cm Rcvista Forensc; v. 293, Janciro-feverciro-março de 1986, p.97.

5. "Dircet Substantial and reasonably foresccable effect". Cf. Herbert Hovemkamp. Federal Antitrust Policy: The Law of Compctition and It's Practicc. Saint Paul: West Publishing, 1994, pp. 699-701. 
desvinculada esta da presença legal e física do agente no Estado do local dos fatos. Cabe considerar, os efeitos (produzidos ou que se possam produzir) como elemento de conexão e critério determinador da aplicação do Direito pátrio.

Em decorrência desses precedentes, tornou-se comum a aplicação das normas antitruste não-somente às práticas cometidas dentro do território da nação cuja jurisdição pretende se exercer, mas também estendendo-se às práticas concretizadas fora do país, desde que produzam efeitos no mercado cuja proteção é objeto da legislação em questão.

Esse rumo tomado pela aplicação das diferentes leis antitrustes deveuse não apenas à influência da Jurisprudência norte-americana, mas ao próprio surgimento e desenvolvimento da legislação antitruste da União Européia, com sua conhecida sistemática de caracterização do ilícito pelos efeitos, para os demais casos do direito de concorrência, sendo os casos de cartel tratados "per se", ou seja, não se examinando eventuais benefícios econômicos decorrentes da prática colusiva, como razão para a exceção da aplicação da punição cabível.

A sistemática norte-americana e européia, comporta a condenação de determinadas condutas, restritivas ao livre mercado, como o cartel, per se. A repressão à produção dos efeitos danosos ao mercado, como a intenção de produzi-los, adotada pela legislação brasileira (Lei n. 8.884/94, em seus arts. 20 e 21) não se põe em contraposição aos conceitos norteadores das primeiras.

As leis de proteção à concorrência da União Européia foram estendidas aos atos praticados fora do território europeu, desde que produzam efeitos no mercado europeu, descritos nos artigos 81 e 82 do Tratado.

Na União Européia, conforme os arts. 81 e 82 do Tratado de Roma são ilícitos os acordos, decisões e práticas concertadas, referidos no n. $1^{\circ}$ do art. 81 do Tratado e a exploração abusiva de posição dominante no mercado, na acepção do art. 82 do Tratado.

Um dos maiores problemas da aplicação extraterritorial das normas antitrustes, em paralelo aos potenciais conflitos entre diferentes jurisdições nacionais, é o da execução da decisão condenatória. Com efeito, na medida em que os réus sejam pessoas jurídicas estrangeiras, sem ativos no território nacional, a execução das penalidades impostas poderia mostrar-se inviável na prática, salvo execução extraterritorial prevista em tratado internacional. Na prática, como se há de apontar, pode-se considerar a retenção legal de remessas da sociedade nacional ao exterior. 
Nesse sentido, a efetividade da aplicação das normas a atos realizados fora do território nacional acaba condicionada à existência de filiais, escritórios ou subsidiárias no território nacional.

Phillip Areeda e Louis Kaplow' ressaltam, como "tendência generalizada, pode-se apontar, terem os tribunais se tornado crescentemente dispostos a considerar a familia corporativa como entidade única, sem consideração excessiva e fastidiosa em relação a distintas personalidades juridicas"

Oportunamente cabe referir o ensinamento de Herbert Hovenkamp, em relação à questão do relacionamento entre matriz e filial: “Outra questão interessante acerca de jurisdição pessoal, que frequentemente, surge nos casos federais antitrustes, é o poder da corte de obter jurisdição sobre a corporação matriz a partir das atividades da sua subsidiária associada."

O enfoque tradicional - e, ressalte-se, predominantemente formalista tendente a considerar a sociedade estrangeira e a nacional como entidades tecnicamente distintas, vem dando lugar ao enfoque e consideração do grupo econômico como todo, cuja ação e estratégias estendem-se por diferentes jurisdições nacionais. Não se trata de querer imputar à sociedade local qualquer papel na configuração da estratégia, mas simplesmente refletir a conexão econômica, no seio de grupo multinacional, independentemente de distintas configurações societárias nacionais. Esta é, normalmente, questão meramente operacional.

Orientação da Lei nacional nesse sentido é claramente seguida pelo art. $26, \S 4^{\circ}$ da Lei n. 8.884/94 - nova redação dada pela Lei N. 10.149/00- : "responde solidariamente pelo pagamento da multa de que trata este artigo, a filial, sucursal, escritório ou estabelecimento, no_País, de empresa estrangeira"

Ainda mais uma vez, a lição de Hovenkamp: "A doutrina Copperweld (...) considera que a matriz e a subsidiária não podem ser consideradas "entidades conspiratórias" para os propósitos do Sherman Act. Esta doutrina é decisiva ou mesmo relevante para a determinação da jurisdição pessoal? A idéia jurisdicional de que acertando a subsidiária não se obtém o mesmo resultado que acertando a matriz, decorre do fato de que as corporações são pessoas jurídicas individuais, com o propósito de servir ao processo. Como resultado a matriz e a sua subsidiária são duas diferentes

6. Phillip AREEDA \& Louis KAPLOW, Antitrust analysis: problems, texts, cases (Boston, LittleBrown \& Co., 4th. cd., 4th. printing, (c) 1988, p. 155): "To spcak gencrally, the Courts may bc said to have become increasingly ready to regard the corporate family as a single cntity, without unduly fastidious regard for scparatc lcgal personalitics" 
pessoas, e o ato de obter jurisdição sobre uma pessoa não cria jurisdição sobre outra qualquer pessoa. Porém a doutrina Copperweld é baseada na conclusão de que, uma vez as formalidades legais postas de lado, a matriz e sua subsidiária são, de fato, entidade única. Pelo menos uma corte notou esta anomalia, concluindo que "para os propósitos da jurisdição e do foro pessoal a corte federal não aceitou como de controle a perspectiva da realidade econômica, que com total clareza e propriedade une a matriz e a subsidiária em um empreendimento com os propósitos exigidos no Sherman Act."

Este enfoque, denota ser a jurisdição pessoal relevante para iniciar e desenvolver o processo, mas não com o fim de determinar a jurisdição sobre o caso, decorrente esta da territorialidade ou da teoria dos efeitos.

Nesse sentido, a analogia Copperweld é de grande valia ao menos quando a matriz é detentora da totalidade ou de participação controladora na subsidiária. A noção de serem as corporações pessoas jurídicas distintas é inteiramente fictícia e, virtualmente, nada tem em relação à extensão na qual a matriz controla sua subsidiária. Quando um grande grupo empresarial considera criar divisão não societária ou subsidiárias em sociedade, o grau de controle é raramente relevante. Tais decisões são norteadas, quase sempre, em sua totalidade, por encargos ou leis tributárias, como a maioria das leis nacionais, que fazem a separação da personalidade corporativa ser relevante. A matriz, proprietária de toda ou da maioria das ações ou quotas da subsidiária não é a mera controladora acionária ausente, mesmo se tiver ocorrido processo doloroso para isolar a matriz das decisões operacionais diárias da subsidiária. ${ }^{8}$

Seguindo esta mesma linha de orientação o já referido art $2^{\circ}, \S 2^{\circ}$ da Lei n. 8884/94, com a nova redação dada pela Lei n. 10.149/00 é cristalinamente claro: " $a$ empresa estrangeira será notificada e intimada de todos os atos processuais,

7. Bchr Automotivc v. Mcrcedes- Benz of N. Am., 1986-2 Trade Cas. 67,261, 61,353, 1985 WL 6417 (E.D. Pa. 1985), affirmed, 800 F.2d II30.

8. "Another interesting question of personal jurisdiction that arises with some frequency in federal antitrust cases is the court's power to obtain jurisdiction over a parent corporation based on the activitics of its scparatcly incorpored subsidiary."

The Copperweld doctrine, discussed in chapter 4, holds that a parent and its subsidiary cannot be "conspiring entitics" for pourposes of $\S 1$ of the Sharman Act. Is this doctrine decisive or even relcvant for pouposes of detcrmining personal jurisdiction? The jurisdiction idea that reaching a parent flows from the fact that corporation's are individualy legal "pcrsons" for the purpose of process. As a result, a parent and its subsidiary are two different "persons", and the act of obtaining jurisdiction over one person does not create jurisdition over somcone clsc. But the Copperweld doctrine is based on the conclusion that, once legal formalitics are cast aside, the parent and its subsidiarics are in fact a single cntity. As least one court has noted this anomaly, concluding that "for purposes of jurisdiction and venuc the fedcral courts 
independentemente de procuração ou de disposição contratual ou estatutária, na pessoa do responsável por sua filial, agência, sucursal, estabelecimento ou escritório instalado no Brasil"

No mesmo sentido do Direito pátrio, no Direito americano, os já mencionados AREEDA e KAPLOW, citando o caso Alcoa, descrevem o relacionamento entre matriz e subsidiária: "Embora a companhia norte-americana, Alcoa, não se considerava membro deste acordo, a ação do cartel estrangeiro estava presumidamente intencionada a induzir Alcoa e a Canadian company, como entidade única para os propósitos antitrustes, porém as descobertas foram em sentido oposto e a corte de apelação, discutiu no instante o assunto da suposição de que a sociedade canadense não era entidade distinta, no comércio norte-americano de aluminio, embora inquestionavelmente presente nos EUA, com o propósito da jurisdição pessoal da corte. A sentença final decidiu que as duas companhias vinham mantendo relacionamento que deveria ser quebrado."

\section{A incidência dos efeitos como nexo causal}

$\mathrm{Na}$ medida em que práticas comerciais concertadas produzam ou possam produzir efeitos sobre determinado mercado, tais efeitos configuram título para exercício da jurisdição, seja esta administrativa ou judicial, de determinado Estado.

Diversamente do artigo $80 \mathrm{CECA}$, os artigos 81 e 82 CEE não restringem o âmbito geográfico de incidência dos dispositivos, não ficando assim vinculados à

\footnotetext{
have not accepted as controlling the perspective of economic reality, wich quite clearly and properly *** links a parent and subsidiary into one enter prise for purposes of Sherman Act liability."

"But Coppreweld analogy is a good onc, at least when the parent owns all or a controlling interest in the subsidiary. The notion that corporations arc separate legal "persons" is intircly fictional and has virtually nothing to do with the extent to wich a parent corporation controls its subsidiarics. When a large firm considers wether to create unincorporrated divisions or separately incorporated subsidiarices, the degrec of control is rarely relevant. Such decisions are driven almost cntircly by liability or tax laws, as wecl as the large number of estatutes that make separete corporate personality relevant. A parent that owns all or most of a subsidiary is not a mere absentec stockholder, cven if it has taken some pains to isolatc itsclf from the subsidiary's daily operational decisions." Herbert Hovemkamp. Fedcral Antitrust Policy: The Law of Competition and It's Practicc. Saint Paul: West Publishing, 1994, pp. 708-709.

9. "Although the U.S company, Alcoa, was not held to be a member of this agrecment, the forcign cartel's actions were presumably intended to induce Alcoa and the Canadian company as a single entity for antitrust purposes, but the findings werc otherwise and the appellate court discussed the instant issuc on the assumption that the Canadian company was a scparatc cntity not in the U.S aluminiun busincss, although unquestionably present in the United Statcs for purposes of the court's in personam jurisdiction. The final decree viewed the two companies as having na interrelationship that had to be dissolved." Phillip Arceda \& Louis Kaplow, Antitrust analysis: problcms, texts, cascs (Boston, Littlc-Brown \& Co., 4th. cd., 4th. printing, (c) 1988, p. 156, nota 140.
} 
situação geográfica da empresa, sendo aplicáveis as normas comunitárias em matéria de concorrência, mesmo que as empresas estejam localizadas ou sejam controladas em terceiro país, configurando a extraterritorialidade de sua incidência, fenômeno de múltiplos e complexos desdobramentos, sobre o qual têm se debruçado expoentes do direito internacional econômico da estatura de Berthold Goldaman ${ }^{10}$ Ignaz SeidlHohenveldern" Francis A. Mann ${ }^{12}$ e muitos outros, dentre os quais George A. van Hecke, Michael Haymann, J.-G. Castel e Isabel Jalles ${ }^{13}$

Trata-se de salientar, possíveis casos da incidência extraterritorial das normas de concorrência, como dado especificamente inovador do ordenamento comunitário europeu, superando dicotomias juridico-conceituais e obsoletas divisões normativas estanques antes consideradas intocáveis, e que se viram não-somente postas em xeque, como superadas pelas necessidades da prática, e substituídas por novos

10. Menção cspecial merccc Bcrthold Goldman, scja por scu curso Le champs d'application territoriale des lois sur la concurrence (RCADI, 1969. III, t. 128, pp. 631/729); ou também, do mesmo, o artigo "Les cffets juridiques cxtraterritoriaux du droit de la concurrence" (R. M. C., 1972, pp. $612 \mathrm{ss}$.), bem como por scu Droit commercial européen (op. cit., Paris, Dalloz, $1^{12}$ cd., 1969; $3^{\text {Ia }}$ cd., 1975); alćm destes, v. tb. a contribuição de Maric-Angèlc Sanson-Hermittc, "La notion de source de droit à l'ćprcuve du droit curopécn de la concurrence" (no vol. coord. por Ph. Fouchard, Ph. Kahn c A. Lyoncacn, Le droit des relations économiques internationales: ćtudes offertes à Berthold Goldman, Paris, Litec, 1983, pp. 299/326).

11. Da rcflexão de Ignaz Scidl-Hohenveldern, destacaria dois cursos na Acadcmia da Haia, inic. International Economic 'soft law' (RCADI, 1979. II, t. 163) c especialmentc seu curso geral, nominalmentc de dircito internacional público, mas de cnfoque sobrctudo cconômico-intcrnacional, intitulado International Economic Law (RCADI, 1986. III, t. 198, pp. 9/264).

12. Francis A. MANN analisou a matćria sobrctudo $\mathrm{cm}$ dois cursos na Academia da Haia, scparados por duas décadas: The doctrine of jurisdiction in International Law (RCADI, 1964. I, t. 111, pp. 1/162) c, vinte anos depois, The doctrine of international jurisdiction revisited after twenty years (RCADI, 1984. III, t. 186, pp. 11/115), b/c, do mesmo, v. tb. nota "The cxtremism of American cxtraterritorial jurisdiction" (I. C. L. Q., 39. 1990, part II, pp. 410/412).

13. Lembre-se o trabalho pionciro de Georges A. van Heckel, Le droit antitrust: aspects comparatifs et internationaux (RCADI, 1962. II, t. 106, pp. 253/356), b/c, do mcsmo, "Règles anti-trust ct concentration d'entrepriscs à l'ćchelon international" (1977; coligido in Misc. Georgcs van HECKE, Antwerpen, Kluwcr, 1985, pp. 85/96).

Dentrc outros, refcriria, i. a.: Michael Hayman, Extraterritoriale Wirkungen des EWGWettbewerbsrechts (tcsc, Baden - Zuriquc, 1974); J. -G. Castcl, The extraterritorial effects of Antitrust Law (RCADI, 1983, t. 179, pp. 9/144); Josć Angclo Estrclla Faria, Selbstbeschränkungsabkommen im GATT und im EWG-Wettbewerbsrecht (Saarbrücken, Europa-Institut, V. R. B. v. 155, 1989);

Em cnfoque comparativo da questão da cxtratcrritorialidade da aplicação das normas comunitárias com o Dirci'o nortc-americano destacaria Isabel JALLES Extraterritorialidade e comércio internacional: um excrcicio de dircito amcricano (Lisboa, Bertrand Ed., 1988; passim), b/c trabalho anterior da mesma autora "A lei da concorrência" análise c perspectivas de aplicação" (in Concorrência cm Portugal nos anos 80, Lisboa, Assuntos Europcus, 1985, pp. 49/74) , b/c, Bcla BALASSA, "The New Protectionism and the Intcrnational Economy" (J. W. T. L., 12. 1978, pp. 409 ss.). 
mecanismos, legalmente revolucionários, de orientação teleológica e economicamente mais pragmáticos. Esta superação de obsoletas divisões normativas estanques, fica patente na real aplicação destas normas comunitárias em decisões recentes, da Comissão:

- Decisão de 24 de outubro de 1996, que aplicou o art. 82 à subsidiária, entendendo ser a matriz e a subsidiária unidade com a mesma linha de ação, ou

- Decisão de 12 de abril de 1999, relativa a processo de aplicação dos arts. 81 e 82 do tratado da União Européia e dos arts. $53^{\circ}$ e $54^{\circ}$ do acordo Espaço Econômico Europeu. ${ }^{14}$

\section{Jurisdição e Significância}

Outro caso de grande valia para o estudo da aplicação extraterritorial das leis, de referência obrigatória, é o Caso Lotus ${ }^{15}$ :"Uma vez que é admitido que os efeitos da ofensa se produziram no navio turco, torna-se impossivel sustentar que existe uma regra de Direito Internacional que proíbe a Turquia de processar o tenente Demons pelo fato de que o autor da ofensa estava a bordo de navio francês"'16

"O efeito do ato, tendo-se produzido em território assimilado à Turquia, justificou, assim, a competência territorial, sob o critério objetivista."

"A pedra de toque desse princípio são os efeitos diretos do evento dentro do território do Estado que, por isso mesmo, fica em posição legítima para conduzir a questão, dentro de sua esfera de competência. É necessário, entretanto, que parte material do evento tenha-se realizado efetivamente dentro do país. De acordo com o princípio subjetivo, o início, a preparação, a realização do ato, cujos efeitos se produzem fora, fundamenta a competência. Pelo princípio objetivo, é o local da consumação, onde os efeitos danosos se fazem sentir, que justifica a asserção da competência." (...)

"Não há, por isso, uma extensão da competência territorial, mas sim o exercício normal dessa competência no próprio território, onde os participantes

\section{Rcc. P. I- 5457. C-73/95 c processo iv/d-1/30.373 - clubes P\&I IGA c iv/d-1/37.143 -}

15. Em uma colisão $\mathrm{cm}$ alto-mar, cntrc um navio francês, Lotus, $\mathrm{c}$ um navio turco, cstc último fundou c pereccram oito tripulantes. O navio francês recolheu os sobreviventes $\mathrm{c}$ os Icvou à Constantinopla, ondc as autoridades turcas prenderam o oficial de serviço, c o processaram por negligência. Com o protesto da França, o caso foi lcvado à Corte Permanente de Justiça Internacional, que após tecer considcrações acerca do problcma da jurisdição territorial, afirmou que tudo o que pode scr cxigido de um Estado ć que não ultrapasse

16. Repertório da Corte Permanente de Justiça Internacional, Sćrie A, n. 10. 
imputáveis do resultado danoso são considerados como que presentes, pelos efeitos de seus atos. Os atores são responsáveis não pelo que fizeram no Exterior, sob outras leis e jurisdições, mas pelos resultados de seus atos no território do Estado, os quais atraem a presença dos mesmos para o local da consumação desses atos. "'/7

Deste modo, percebe-se a extensão em que o efeito concreto sobre o mercado, como dimensão privilegiada e crucial da proteção dos interesses nacionais, pode decorrer de atos formalmente praticados sob outra jurisdição. Se e na medida em que o impacto de referidos atos ou práticas teve conseqüências danosas sobre o mercado nacional, configura-se, validamente, a pretensão de estender o exercício da jurisdição (quer administrativa como judicial) nacional, para coibir e reprimir tais práticas.

Paralelos podem ser, ainda neste passo, invocados à guisa de ilustração. Nesse sentido, ensinam Areeda e Kaplow: "O Sherman Act não tem a intenção de correr o mundo comercial; porém declarar que somente efeitos significativos no comércio exterior norte-americano são protegidos não identifica o limiar da significância. Significância consegue ser determinada pela dificuldade factual na avaliação dos efeitos no comércio dos EUA ou, assumindo a jurisdição, pelo julgamento qualitativo da racionalidade e a prudência, ou balanceando os interesses domésticos e exteriores. "Is

A orientação da Jurisprudência brasileira não poderia ser infensa a estes rumos, seja julgamento recente, emanado do Superior Tribunal de Justiça (2000) ${ }^{19}$ como precedente ilustre, julgado há quase cem anos, pelo Supremo Tribunal Federal $(1906)^{20}$ Guardadas algumas nuances de linguagem, sinal dos tempos, vale ter presente a consistência da orientação.

17. Josć Carlos de Magalhãcs, "A aplicação cxtratcrritorial de Icis nacionais", cm Revista Forense, vol. 293, janciro-feverciro-março de1986, pp.95.

18. "The Sherman Act is presumably not intended to run the commercial world, yet to say that only significant effects on United States foreign commerce are covered does not identify the threshold of significance. Significance can be determined by the difficult factual assessment of the effects on United States commerce or, assuming jurisdiction, by the qualitative judgment of the reasonableness of the restraint, or by balancig forcign and domestic interests." 18 Phillip Arecda \& Louis Kaplow, Antitrust analysis: problems, texts, cases (Boston, Littlc-Brown \& Co., 4th. ed., 4th. printing, (c) 1988, p. 162).

19. Recurso especial - 63.981 - SP. Plínio Gustavo Prado Garcia v. Panasonic do Brasil Ltda.

20. Supremo Tribunal Federal, $1^{\circ}$ dezcmbro, 1906 -Doutor Coclho Rodriguez c. New York Lifc insurance Co. - Pres. M. Piza c Almeida - O dircito, v. 105, pp. 235 
Jurisprudência recente do S.T.J.

Acordão recente, datado de 11 de abril de 2000 (no âmbito do julgamento do Resp. 63.981-SP) o Superior Tribunal de Justiça, em ementa aponta a medida na qual o fenômeno da globalização vem trazendo conseqüiências inevitáveis:

"Se a economia globalizada não mais tem fronteiras rigidas e estima e favorece a livre concorrência, imprescindivel que as leis de proteção ao consumidor ganhem maior expressão em sua exegese, na busca do equilíbrio que deve reger as relações juridicas, dimensionando-se, inclusive, o fator risco, inerente à competitividade do comércio e dos negócios mercantis, sobretudo quando em escala internacional, em que presentes poderosas, multinacionais, com filiais em vários paises, sem falar nas vendas hoje efetuadas pelo processo tecnológico da informática e no forte mercado consumidor que representa o nosso pais."

O Ministro Cesar Asfor Rocha, em voto-vista, assim se manifestou, nesse mesmo REsp.:

"É por todos consabido que a realidade atual indica que estamos vivendo em um mundo de economia globalizada.

Hoje é numerosa a existência de grandes corporaçôes supra-nacionais que até podem ter a principal sede de negócios em um determinado país sem que contudo, nele estejam sendo necessariamente exercidas as suas atividades ou sendo auferidos os seus maiores lucros.

Essas grandes corporações perderam a marca da nacionalidade para se tornarem empresas mundiais. Sairam do provincianismo e alcançaram a universalidade.

É certo que podem até ter, por conveniências políticas, contábeis ou fiscais, em cada pais, uma personalidade jurídica distinta, mas que se acham unidas por receberem a mesma atuação estratégica, e guardarem em comum a sujeição a um mesmo comando.

Nenhuma delas é uma ilha isolada, tanto que a propaganda, ainda que possa respeitar determinadas peculiaridades locais, é a mesma em todos os cantos, sobretudo no que se reportar a consolidar a fixação de sua marca."

Por sua vez, o Ministro Ruy Rosado de Aguiar, proferiu o seguinte votovogal :

"A empresa que vende seus produtos em diversos países do mundo, e assim se beneficia do regime de globalização comercial, deve responder pelas suas obrigações com a mesma extensão. A quebra das fronteiras para a venda há de trazer 
consigo a correspondente quebra das fronteiras para manter a garantia da qualidade do produto. Do contrário, a empresa multinacional receba o bônus que significa a possibilidade de ampliar o mercado para a colocação da mercadoria que produz, elevando-o a um plano universal, mas se exonera do ônus de assumir a responsabilidade de fabricante ou fornecedor, invocando a seu favor a existência da fronteira. Esse limite, que não impede a sua expansão, não pode servir para reduzir a sua obrigação."

Além da experiência legislativa, administrativa e doutrinária, tanto dos EUA quanto da União Européia, critérios similes são adotados pelo Direito brasileiro, seja na Lei n.8884/94, como neste acordão recente do STJ (2000). O efeito concreto sobre determinado mercado é critério relevante e pode ser validamente invocado pelo Estado, seja judicial como administrativamente, para fazer valer o exercício da Jurisdição nacional, em relação a caso concreto.

Muito antes que se cogitasse do processo de globalização e seus epifenômenos, sobremodo instrutivo e valioso precedente emanado do Supremo Tribunal Federal, no início do século XX.

Precedente Histórico do Supremo Tribunal Federal.

O Supremo Tribunal Federal em sessão de primeiro de setembro de 1906, analisando questão relativa a competência do judiciário nacional em relação à uma sociedade estrangeira, assim se manifestou:

1. sociedade estrangeira operando no Brasil, fica submetida, para suas operações feitas nesse país, à competência dos tribunais brasileiros.

2. Ela não pode se subtrair a essa regra, que é de ordem pública, valendo-se de convenções consentidas por seus clientes ou a estes impostas, as quais atribuiriam competência aos tribunais da sede social no exterior.

Ementa: Considerando que o Dr. Coelho Rodriguez pleiteia contra New York Life a anulação de contrato de seguro de vida, que a Companhia suscitou perante o juiz federal de nossa capital a exceção de incompetência, que encontrou acolhida da qual apelação foi apresentada dessa decisão; - considerando que referida decisão carece de fundamento juridico, e que esta contém clausula da apólice que configura violação dos princípios de nosso direito; (...) ; que esta pode ser aceita pelo apelante como acarretando atribuição de competência a jurisdição estrangeira para atos celebrados no território brasileiro, mas que esta não poderia ver sancionados pelos tribunais, e deve, como ilícito, ser reputada não escrita e inexistente; considerando que se trata 
de apreciar e julgar os atos de sociedade estrangeira autorizada, que a questão pode suscitar conflito de leis ou debate de direito internacional, que constitui, como tal, a competência do juiz federal; o Supremo Tribunal recebe a apelação, devolve ao conhecimento do juiz federal e conden a intimada ao pagamento das custas.

Nota: a decisão do primeiro juiz estava motivada em "mediante cláusula formal as apólice, as partes tinham atribuído competência, para todas as dificuldades decorrentes do contrato, aos tribunais de Nova York, os quais eram justamente os do domicílio da ré"

Quer o caso recente, do STJ, como o precedente, do STF, não-obstante a natureza distinta, visto tratar-se de obrigação decorrente de contrato, no caso julgado pelo STF, perfeitamente cabíveis as considerações expendidas pelo Pretório Excelso com relação aos limites da jurisdição nacional, dada a ocorrência de "atos celebrados no território brasileiro" sob pena de "não poder ver sancionados pelos tribunais" a conduta lesiva aos interesses e ao mercado nacional. Falacioso como pernicioso seriam os efeitos da pretensão de afastamento da jurisdição nacional.

Caberia, ainda, destacar a inadequação de se intentar paralelo entre a lei $8884 / 94$ e o direito penal.

Natureza Não-Penal Lei n. 8.884/94

O princípio da livre concorrência tem caráter instrumental ao princípio da livre iniciativa, na medida em que constitui elemento a balizar o seu exercício, a fim de que esta livre iniciativa exercida dentro de suas finalidades sociais, mantendo condições propícias à atuação dos agentes econômicos, de um lado, e beneficiando os consumidores, de outro.

É importante notar, porém, que a livre concorrência não constitui corolário da livre iniciativa, vale dizer, não é consequiência natural, ou mero desdobramento desta. Com efeito, à medida em que se constatou ser o mercado falho na alocação de recursos e na manutenção do jogo concorrencial, não foi mais possível identificar a livre concorrência como subproduto da livre iniciativa. Nesse sentido, embora complementares, livre iniciativa e livre concorrência têm conteúdos diferentes ${ }^{21}$

Quanto ao seu conteúdo, o princípio da livre concorrência, costuma ser identificado com a liberdade de atuar nos mercados, buscando a conquista de clientela, com a expectativa de sua aplicação levar os preços de bens e serviços, fixados pelo jogo 
dos agentes, em disputa pela clientela, a níveis razoavelmente baixos, chegando no caso extremo de concorrência perfeita a se igualarem ao custo marginal do produto ${ }^{22}$. Apontase, no entanto, que à liberdade jurídica de conquista de clientela pelos concorrentes, deve somar-se a liberdade dos consumidores de usufruírem de alternativas ${ }^{23}$

A proteção constitucional à livre concorrência, no entanto, não pode ser confundida com a manutenção das condições de concorrência perfeita, na qual não há qualquer manifestação do poder econômico de agentes no mercado. Ao contrário, o fenômeno do poder econômico é até mesmo reconhecido constitucionalmente, noß 4". do art. 173 que prescreve a repressão ao seu abuso.

Nesse sentido, afirma Tércio Sampaio FERRAZ Jr.: "o mundo capitalista desenvolvido já percebera há muito tempo a profunda alteração sofrida pela concepção oitocentista do mercado concorrencial. Aceitava-se agora tratar-se de um processo comportamental competitivo, que admite gradações tanto na atomicidade quanto na fluidez de sua estrutura. É é este elemento comportamental - a competitividade - que passa a definir a concorrência. A competitividade exige a descentralização de coordenação como base da formação dos preços, o que supõe livre iniciativa e apropriação privada dos bens de produção. Isto faz com que a luta, no interior do mercado, receba um novo peso estrutural. Ela não é apenas ativadora do processo, mas elemento que o regula e, no limite, altera a própria estrutura" 24

Assim, a interpretação do sentido do princípio da livre concorrência passa pela compreensão dos fenômenos das economias de escala na indústria moderna e da necessidade de se garantir a eficiência econômica nos mercados, com o privilégio à conduta competitiva das empresas. A análise contextual da competitividade de cada setor econômico leva à relativização da aplicação de modelos de análise a priori do funcionamento dos mercados a partir de sua estrutura. No caso do controle dos atos de concentração nas economias contemporâneas, a capacidade de compreensão e análise por parte das autoridades competentes para a decisão é essencial.

$\mathrm{O}$ aspecto mais importante a ser abordado com relação ao princípio da livre concorrência, todavia, diz respeito ao seu papel na fundamentação da legislação

22. Isso se $\mathrm{c}$ na medida $\mathrm{cm}$ que se possa pretender o funcionamento dos mercados sob regime de concorrência perfeita.

23.Cf. Rocha. op. cit., p. 16.

24. Lci de defesa da concorrência: origem histórica c base constitucional. Arquivos clo Ministério da Justiça, Brasilia, 1992, p. 178. 
de proteção à concorrência. No Brasil, ela levou, inclusive, a alterações na disciplina da ordem econômica na Constituição, de 1988, com relação àquelas que a antecederam ${ }^{25}$

Com efeito, desde a Constituição, de 1946, prevê-se a existência de direito da concorrência, a partir da regra que determinava a repressão dos abusos do poder econômico. Em 1967, essa regra passou a integrar o capítulo da ordem econômica ${ }^{20}$ o que foi mantido pela Emenda 1/69. Na Constituição atual, embora conservado, o princípio da repressão ao abuso do poder econômico teve sua importância deslocada, compondo a disciplina de artigo referente à exploração de atividade econômica pelo Estado ( $\left(4^{\circ}\right.$ do art. 173). Simultaneamente, incluiu-se o princípio da livre concorrência entre os definidores da ordem econômica (no inciso IV do art. 170).

Nesse sentido, a partir das inovações, trazidas pela Constituição, de 1988, à disciplina da Ordem Econômica, deve-se concluir ser o princípio da livre concorrência e não o da repressão ao abuso do poder econômico o fundamento da lei antitruste (lei 8.884/94), conclusão esta de importância na definição da natureza da lei.

A disciplina de repressão às lesões à concorrência, anteriormente à Constituição atual, era tida como penal ${ }^{27}$, em função da "linguagem da finalidade" ${ }^{28} \mathrm{e}$ do estilo tipificante ${ }^{29}$ utilizada por esses textos constitucionais. Assim, apesar de a lei então vigente (Lei n. 4.137/62) estabelecer mecanismo de regulação a priori e não apenas de repressão a posteriori, caracterizadores de seu caráter penal-administrativo, a lei foi predominantemente entendida como penal pelos seus aplicadores e pela doutrina $^{30}$

A Lei n. 8.884/94, editada a partir de disciplina constitucional inovadora do tratamento da proteção à livre concorrência, não pode ser analisada, como aparentemente fundamentada no dispositivo do $\S 3^{\prime \prime}$ do art. 173 da Constituição,

25. Essa análise ć claborada por Rocha, op. cit., p. 7 c 20-26.

26. O art. 157 da constituição de 1967 dispunha: "A ordem cconômica tem por fín realizar a justiça social, com base nos seguintes princípios: (...) VI - repressão ao abuso do poder cconômico, caractcrizado pclo domínio dos mercados, a climinação da concorrência c o aumento arbitrário dos lucros"

27. Cf. nesse sentido, Pontes de Miranda. Comentários à Constituição de 1967. 2a. cdição. São Paulo: Editora Revista dos Tribunais, Tomo IV, 1969, p. 50.

28. "Linguagem da finalidade" diz respeito ao texto da Constituição de 1946 que falava no abuso do poder cconômico que "tenha por fim...", influenciando toda a doutina antitruste a partir de cntão.

29. Cf. B. Schicber. op. cit., p. 28.

30. Cf. Fcrraz Júnior.Lei de defesa. op. cit, p. 178- 180. 
mantendo-se sua filiação à interpretação construída no passado, impondo-se a conclusão de ter a atual lei caráter econômico.

$\mathrm{Na}$ medida em que foi retirada a repressão ao abuso do poder econômico da listagem dos princípios da ordem econômica constitucional e incluída nesta a livre concorrência, a Lei n. 8.884/94 comporta outro tipo de interpretação. A conformação dada à ordem econômica na Carta não apenas erige a livre concorrência como princípio, mas estabelece a priorização do valor social da livre iniciativa, para o que a proteção às condições efetivas de concorrência nos mercados é essencial. Nesse sentido, fica legitimada, constitucionalmente, a criação de lei de proteção à concorrência composta de mecanismos sancionatórios às infrações contra a concorrência , mas também, de mecanismos de caráter regulador do mercado, típica de Direito Econômico, tal como exemplifica o seu art. 54, estabelecendo o controle de atos de concentração. A Lei n. 8.137, por sua vez, trata da disciplina penal às infrações contra a ordem econômica, regulamentando o $\$ 4^{\circ}$ do art. $173^{31}$

\section{Conflitos de Leis em Direito Antitruste}

Em matéria de direito antitruste, como bem aponta Marc-André Renold, o simples fato de determinada sociedade ser estrangeira e agir no Exterior não deve nem pode necessariamente significar que a legislação econômica de um Estado não se aplica, mesmo quando a atividade desta sociedade tem relevante impacto no econômico no território desse Estado. Em grande número de casos os Estados, e muito particularmente os EUA, adotaram esse segundo enfoque para determinar a aplicabilidade de sua própria legislação econômica. Daí resultou amplo de aplicação correntemente qualificado de extraterritorial. ${ }^{32}$

Não seria descabida, nem tampouco caso isolado, a adoção do critério

31. Nessc scntido, Eros Grau (op. cit. p. 232) afirma: "Notc-sc bem que a Lci n. 8.884/94 não veicula matćria penal; a matćria penal, relativa à concorrência c à ordem cconômica ć regulada pcla Lci 11. 8.137, de $27 / 12 / 90$, que permancce vigente". O autor reforça csse argumento a partir do tcor do artigo 20 da Lci n. 8.884/94 que cstabclecessc responsabilidade objetiva aos autores das infrações lá descritas, incompative! com o Dircito Penal. (p. 235).

32."Pourquoi le simple fait qu'une socićté soit ćtrangère ct agissc à l'ćtranger devrait-il nécessaircment significr que la législation ćconomique d'un Etat ne s'applique pas, même si l'activité de cette société a un important impact ćconomique dans le territoirc de cet Etat? Dans un assez grand nombre de cas les Etats, ct tout particulic̀rement les Etats-Unis, ont adopté cettc seconde approche pour déterminer l'applicabilité de lcur propre lćgislation ćconomique. Il cn cst résultć un champd'application ćtendu que l'on qualific couramment d'extraterritorial." Marc-André Renold, "Les Conflits de Lois en Droit Antitrust", Zurique, 1991, pp. 139. 
dos efeitos como elemento de conexão, como ressalta o mesmo autor: "É fácil constatar que, usando exatamente a liberdade que lhes confere o direito internacional público, os Estados freqüentemente adotaram o critério dos efeitos para delimitar o âmbito de aplicação de sua legislação. A prática das autoridades nacionais, se baseia amplamente (....) no critério dos efeitos. É interessante ressaltar que determinadas decisões $e$ declarações oficiais recentes admitem expressamente a validade dos efeitos como elemento de conexão, à luz do direito internacional público. Desse modo no caso Sensor ${ }^{33}$, julgado em 1982, pelo tribunal da comarca da Haia, se colocava a questão de saber se o embargo americano declarado em relação à construção do gasoduto euro-siberiano poderia afetar um contrato celebrado entre duas sociedades européias e regido pelo direito holandês. O tribunal holandês examinou a validade da reivindicação de competência dos EUA face ao direito das gentes e considerou que se operações de exportação 'tem efeitos diretos e proibidos no território dos EUA' estas podem ser consideradas submetidas à jurisdição americana segundo as regras geralmente admitidas de direito internacional público ".34

"Generalizando a leitura do caso (Lotus), emanado da Corte Permanente de Justiça, chega-se a conclusão o critério dos efeitos está longe de ser inaceitável em direito internacional público, na medida em que este é a expressão de vínculo suficiente com o ordenamento juridico cuja lei reivindica aplicação. Na mesma ordem de idéias, um autor ${ }^{35}$ recentemente demonstrou que a utilização do critério dos efeitos para determinar a aplicabilidade do direito antitruste corresponde à exigencia de

33. Tribunal d'arrondissement de La Hayc, Compagnic Europćcnne des Pćtroles, S.Ac. Scısor Nederland B.V., 17 scptcmbrc 1982, RabclsZ 47 (1983) 141 = ver. Crit. 72 (1983) 473.

34. "Il aisć de constater que, faisant précisćment usage de cette libertć que leur laissc le droit intemetioncl public, les Etats ont frćquemment retenu le crit]]]ćre des cffets pour délimiter le champ d'application de lcur législation. La pratique des autorités nationales s'appuic en effet très amplesant de relcver que certaincs décisions et déclarations officiclles récentes droit international public. Ainsi dans l'affairc Sensor, jugćc cn 1982 par lc Tribunal d'arrondissement de La Hayc, sc posait la question de savoir si l'cmbargo amćricain prononcé àl'cncontrc dela construction du gazoduc curo-sibćricn pouvait affecter un contrat passć cntrc dcux socićtćs curopécnnes et soumis au droit nćcrlandias. Le tribunal nécrlandais cxamina la validitć de la renendication de compétenec des Etats-Unis face au droit des gens ct considéra que si des općrations d'cxportation "ont des cffets directs ct interdits sur le territoirc des Etats-Unis", clles peuvent ĉtrc considérćcs "comme soumises à la juridiction amćricaine sclon les règles génćralement admises de droit international public" Tecl n'ćtait cependant pas, aux ycux du tribunal nécrlandais, le cas en l'espècc." Marc-Andrć Renold, "Les Conflits de Lois en Droit Antitrust", Zurique, 1991, pp. 148.

35. MEESSEN, Karl Matthias - Volkerrechhtlichc Grundsätze des internationalem Kartellrechts, BadenBaden, 1975. 
racionalidade do direito das gentes, exigência que se exprime pelo termo alemão de vínculo significativo (sinnvolle Anknüpfung). Para se convencer que esta condição está configurada, basta ter presente os muito sólidos fundamentos sobre o quais repousa o critério dos efeitos, o que é muito mais convincente na medida em que a prática estatal muito freqüentemente recorre a este critério" .36

\section{Conclusão}

Ao longo deste artigo, foi demonstrada a evolução da aplicação extraterritorial da legislação antitruste como conseqüiência da evolução da internacionalização da economia, não-somente doutrinariamente, mas jurisprudencialmente, destacando-se a teoria dos efeitos e sua validade como elemento de conexão à luz do Direito Internacional Público, as diferenças da legislação antitruste brasileira em relação à européia e a norte-americana, destacando-se entre estas: o tratamento "per se" e a responsabilidade objetiva e a natureza não-penal da legislação pátria antitruste 37

São Paulo, maio de 2001.

36. "En gćneralisant cette lecture de l'arrĉt de la Cour Permanente de Justicc, l'on en arrive à la conclusion quele critère des effects cst loin d'être inacceptable en droit international public dans la mesure où il cst l'cxpression acceptable en droit international public dans la mesurc où il cst l'expression d'un lien suffisant avec l'ordre juridique dont la loi revendique l'application. Dans le même ordre d'idécs, un autcur a récemment démontré que l'utilisation du critère des effects pour déterminer l'aqpplicabilité du droit antitrust correspond à l'exigence de rationalité du droit des gens, exigence qu'il exprime par le tcrme allemand de "sinnvollc Anknüpfung". Pour se convaincre de ce que cette condition est réalisćc, il suffit de garder à l'csprit les trés solides fondements sur lesquels repose le critère des ecffets, ce qui cst d'autant plus convaincant que la pratique c̀tatique a le plus souvent recours à ce critèrc."

37. Nesse scntido, cfr. de Paulo B. CASELLA c Ana M. de Olivcira NUSDEO, "Competition policy in Brazil" in Polityka konkurencji w krajach wschodzacych rynków, coord. Roman PATORA c Ryszard PIASECKI, Kolegium Wydawnicze Spolcczncj Wyzszej Szkoly Przedsicbiorczosci i Zarzadzania w Lodzi. Lodz, 2001, v. I, pp. 189-198.

$\mathrm{O}$ enfoque da necessidade c alcance das regras de proteção à livre concorrência sc coloca cm relação a paises da Amćrica Latina c Europa Central, com destaque para a situação prescnte da Polônia. 